\title{
Investigation of lonospheric Response to Geomagnetic Storms over a Low Latitude Station, Ile-Ife, Nigeria
}

\author{
Oluwaseyi E. JIMOH ${ }^{1}$, Thomas K. YESUFU ${ }^{2}$, and Emmanuel A. ARIYIBI ${ }^{1}$ \\ ${ }^{1}$ Department of Physics, Obafemi Awolowo University, Ile-Ife, Nigeria; \\ e-mail: oluwaseyi.jimoh@gmail.com \\ ${ }^{2}$ Department of Electronic and Electrical Engineering, \\ Obafemi Awolowo University, Ile-Ife, Nigeria
}

\begin{abstract}
Due to several complexities associated with the equatorial ionosphere, and the significant role which the total electron content (TEC) variability plays in GPS signal transmission, there is the need to monitor irregularities in TEC during storm events. The GPS SCINDA receiver data at Ile-Ife, Nigeria, was analysed with a view to characterizing the ionospheric response to geomagnetic storms on 9 March and 1 October 2012. Presently, positive storm effects, peaks in TEC which were associated with prompt penetration of electric fields and changes in neutral gas composition were observed for the storms. The maximum percentage deviation in TEC of about 120 and $45 \%$ were observed for 9 March and 1 October 2012, respectively. An obvious negative percentage TEC deviation subsequent to sudden storm commencement (SSC) was observed and besides a geomagnetic storm does not necessarily suggest a high scintillation intensity $\left(\mathrm{S}_{4}\right)$ index. The present results show that magnetic storm events at low latitude regions may have an adverse effect on navigation and communication systems.
\end{abstract}

Key words: geomagnetic storm, prompt penetration electric field, total electron content, scintillation, percentage deviation. 


\section{INTRODUCTION}

It has become very important to investigate the ionospheric dynamics and disturbances during geomagnetic storms. This is majorly due to the significant role which the ionosphere plays in the transmission of radio signals from space borne satellites to ground based receivers. The ionosphere induces a time delay in transionospheric radio signals (Davies 1990). The changes in the ionosphere that follow geomagnetic storms could result in severe scintillations that disrupt radio communications and/or cause large changes in ionization that can over/under estimate the ionospheric corrections required in some applications (Chandra and Rastogi 2011). The primary causes of geomagnetic storms on the Earth are strong interplanetary electric fields associated with the passage of southward directed magnetic fields $(B z)$ past the Earth for a sufficiently long interval of time (Gonzalez et al. 1994). When $B z$ is strongly negative, magnetic reconnection between the interplanetary magnetic field (IMF) and the geomagnetic field produces open field lines which allow mass, energy, and momentum to be transferred from the solar wind to the Earth's magnetosphere (Davis et al. 1997). Some factors determining ionospheric variation during magnetic storm are the alteration of the neutral composition and the thermospheric circulation (Ariyibi et al. 2013a).

There are several studies on responses of low latitude ionosphere to magnetic storms events (Sobral et al. 1997, Sastri et al. 2000, Pincheira et al. 2002, Abdu 2001, Lobzin and Pavlov 2002a, b; Pavlov et al. 2004, Lynn et al. 2004, Lima et al. 2004, Dashora et al. 2009, de Siqueira et al. 2011, D'ujanga et al. 2013). A number of studies by Nigerian researchers have also been conducted on low latitudinal ionosphere responses during magnetic storm periods that have contributed to our understanding on this subject (Adeniyi 1986, Olawepo and Adeniyi 2012, Olawepo 2013, Ariyibi et al. 2013a).

Ionospheric conditions have tremendous impact on navigation and communication. In this regards, the variation of TEC of the ionosphere should be studied to mitigate the possible effects this might have on navigation and communication systems. There is still the need to examine and understand the processes that lead to an ionospheric storm and variation in TEC during geomagnetic storm, especially over the African ionosphere where a lack of technological development and data paucity are hampering research efforts. In this paper a study which investigates the ionospheric response to two intense geomagnetic storm events which occurred on 9 March and 1 October 2012 at a low-latitude station, has been carried out at Ile-Ife (Lat. $7.55^{\circ} \mathrm{N}$, Long. $4.55^{\circ} \mathrm{E}$, Dip Lat. $7.50^{\circ} \mathrm{N}$ ) in Nigeria. The result of this research will 
provide valuable inputs to the understanding of the equatorial ionosphere (Ile-Ife) especially during magnetic storm events.

\section{MATERIALS AND METHODS}

The NovAtel GSV 4004B GPS receiver which is specifically configured to measure amplitude and phase scintillations from the L1 frequency GPS signal, and the ionospheric TEC from the L1 and L2 frequency GPS signals, was used in this experiment. It recorded the TEC and $\mathrm{S}_{4}$ index at Ile-Ife, Nigeria. The solar wind and the geomagnetic indices data used for this study consist, respectively, of hourly values of plasma speed, Interplanetary Magnetic Field (IMF- $B z$ ) which were obtained from the OMNI database, http:// cdaw.gsfc.nasa.gov, and $D s t, K p$, and AE indices, obtained from the World Data Centre (WDC) Kyoto, Japan. The ionospheric data was processed and analysed using the GPS-TEC analysis application user's manual software, developed in 2010 by Gopi Seemala, Institute of Scientific Research, Boston College, Chestnut Hill, Massachusetts. This software reads raw data, gets ephemeris from IGS navigation file, has the ability to download the navigation file automatically if connected to internet; unless it finds the file in the same directory as data, processes cycle slips in phase data, reads satellite biases from DCB International GNSS Service (IGS) code file (if not available, it calculates them), calculates receiver bias, and calculates the inter-channel biases for different satellites in the receiver. Since the data at the satellite elevation angle lower than $20^{\circ}$ may be corrupted due to multi-path and higher horizontal gradients, data with minimum elevation angle of $20^{\circ}$ is used. It gives plots of the vertical TEC values on screen and writes ASCII output files in the same directory of data file. Besides, further analysis of the data was carried out and owing to the fact that changes in the ionosphere are more evident in TEC deviation from the monthly average (Malik et al. 2010), hence the degree of disturbance was estimated by the TEC deviation from the monthly average quiet TEC:

$$
\delta \mathrm{TEC}=\left(\mathrm{TEC}_{\mathrm{obs}}-\mathrm{TEC}_{\mathrm{avg}}\right) \times 100 / \mathrm{TEC}_{\mathrm{avg}} \%,
$$

where $\mathrm{TEC}_{\mathrm{obs}}$ is the observed value of the TEC and $\mathrm{TEC}_{\mathrm{avg}}$ is the monthly average quiet TEC value. Besides, the storm time manifestations in the ionosphere were explained using the observed peaks in TEC. The variation of TEC was discussed with reference to the geomagnetic index, Dst. When estimating TEC and scintillation from GPS observations, the ionosphere was approximated by a spherical shell model at fixed height of $350 \mathrm{~km}$ above the Earth surface. The TEC was obtained by leveling the phases to the pseudoranges to give the relative TEC and followed by the estimation/removal of the instrumental biases (calibration) to give the absolute TEC. A simple 
geomagnetic factor was used to convert the slant TEC into a vertical one (VTEC). All TEC data were presented in TEC units $\left(1 \mathrm{TECU}=10^{16} \mathrm{el} / \mathrm{m}\right)$. The $\mathrm{S}_{4}$ index has been used to estimate the intensity of the scintillation.

\section{RESULTS}

\subsection{Solar interplanetary and geomagnetic observations during the storm event of 7-11 March 2012}

The observation for the storm which occurred on 9 March 2012 is indicated in Fig. 1. This figure shows the solar wind speed $(V p)$, southward component of the interplanetary magnetic field (IMF-Bz), disturbance storm time (Dst), $K p$ and $\mathrm{AE}$ indices from the top to the bottom panel, respectively, for the period 7-11 March 2012.

The solar wind speed was less than $600 \mathrm{~km} / \mathrm{s}$ on 7 March. It increased sharply with a notable peak of about $700 \mathrm{~km} / \mathrm{s}$ at noon on 8 March, and it remained high throughout the day. It further increased to a maximum value of about $740 \mathrm{~km} / \mathrm{s}$ at 13:00 UT on 9 March and had gradual decrease for the rest of the day during the recovery phase of the storm. The IMF- $B z$ was southward for most of 7 March, fluctuating between 0 and $-10 \mathrm{nT}$; however, at 22:00 UT it turned northward. It remained in the northward direction for about 14 hours with a peak value of $15 \mathrm{nT}$ at 12:00 UT on 8 March. It further turned southward to attain a value near $0 \mathrm{nT}$ and fluctuated about this value for about 6 hours between the periods of 15:00-20:00 UT. However, it turned northward again for about 6 hours between 21:00 UT on 8 March to 01:00 UT on 9 March. It then turned negative, abruptly reaching a minimum value of about $-16 \mathrm{nT}$ at 07:00 UT, showing that on the day of the storm the IMF- $B z$ changed value from about 15 to $-16 \mathrm{nT}$ within a period of 7 hours, during the post midnight and the early morning hours. It gradually began to recover to its initial values and remained continuously negative all through the recovery phase. The Dst values were generally near and below zero for the days considered, except at about noon on 8 March when there was a sudden increase to $40 \mathrm{nT}$, marking the SSC time as shown by the arrow on the Dst panel in Fig. 1, which was followed immediately by a negative decline to $-30 \mathrm{nT}$ at 18:00 UT and attained same value at 23:00 UT before it had a large decrease to a value of about $-140 \mathrm{nT}$ at 09:00 UT on 9 March. The $K p$ values of 6 and less were observed for 7 March, indicating active condition. There was a drop to 1 between 03:00-05:00 UT on 8 March, and afterward it increased to attain a peak value of 8 between 06:00-08:00 UT on 9 March; it maintained moderate activity all through the recovery phase. The SSC synchronized with sudden increase in AE index some minutes before 12:00 UT on 8 March 2012. The AE index attained a maximum value of $1785 \mathrm{nT}$ at about 09:00 UT, some 4 hours after PPE. 


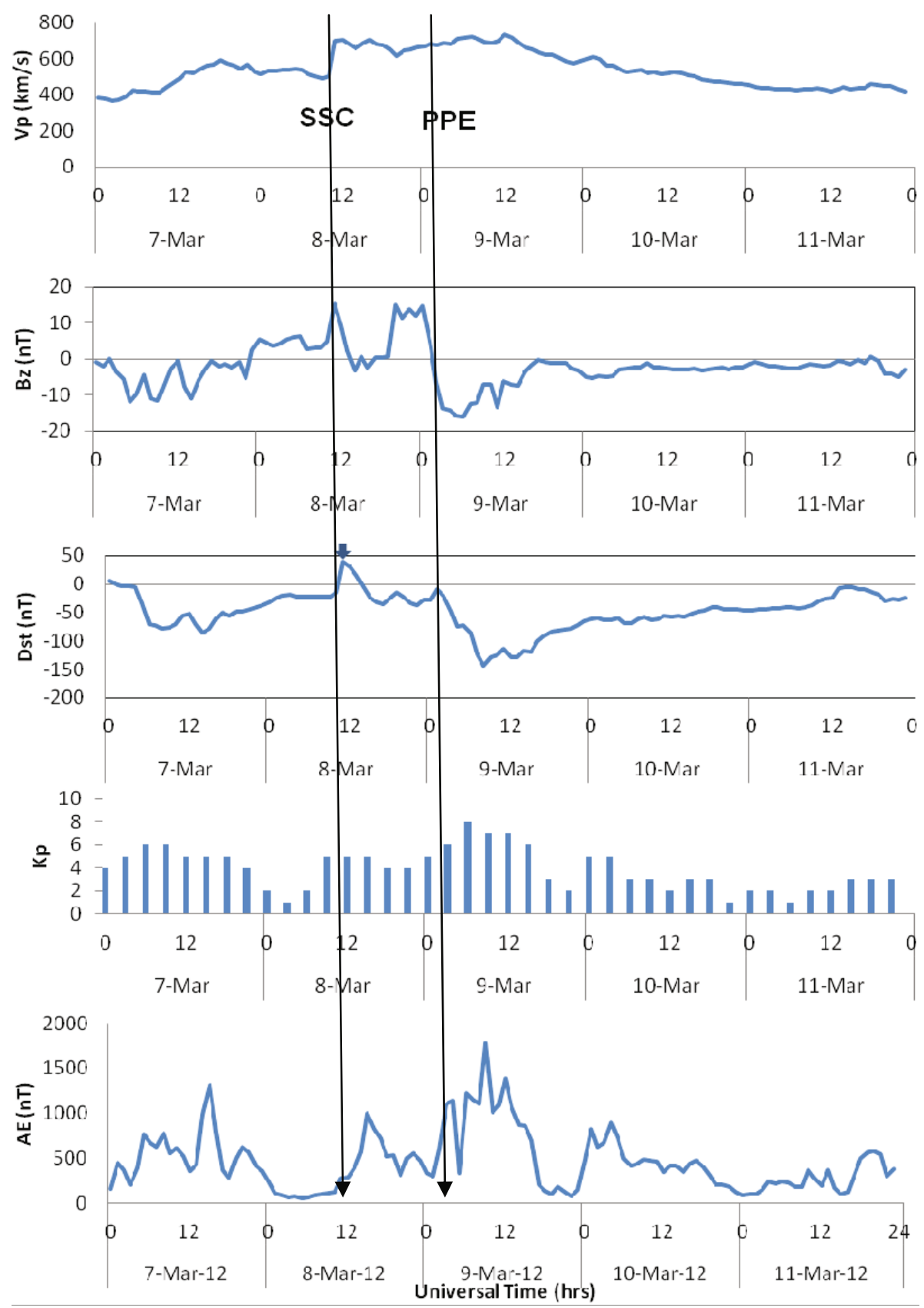

Fig. 1. The interplanetary and geomagnetic observations for the period of 7-11 March 2012. The arrow on Dst is indicating the SSC. 
Generally, it is seen from Fig. 1 that at the SSC time there was an abrupt increase in solar wind speed which, according to Hargreaves (1995) appears to confirm the presence of a shock in the interplanetary medium at about 11:00 UT. There were more fluctuations in IMF- $B z$ at the initial phase of the storm compared to the recovery phase which was characterized by gentle fluctuations. And there is a correlation between the minimum $D s t$ value and the maximum $K p$ value. The $\mathrm{AE}$ also indicated high auroral activities during the main phase of the storm, as energy is coupled into the ionosphere.

\subsection{Ionospheric response to the geomagnetic storm of 9 March 2012: VTEC and $S_{4}$ data}

Figure 2 shows the VTEC plots for all available Pseudo Random Numbers (PRNs) on 8, 9, and 10 March 2012, respectively. These VTEC plots exhibited the typical features of three segments expected of a VTEC curve from a low-latitude station, as reported by Bagiya et al. (2009). The VTEC of 8 March decreased from about 25 TECU at 00:00 UT to less than 5 TECU between 04:00-06:00 UT, from where it gradually rises to a peak value of 65-70 TECU between the periods of 12:00-16:00 UT with slight depression around the 14:00 UT. It gradually falls afterward exhibiting the usual plasma fluctuations during the evening pre-reversal with a value of $30 \mathrm{TECU}$ at 23:00 UT. On 9 March, the feature in VTEC curve as observed on 8 March was repeated, till around 09:00 UT when there was an abrupt increase in VTEC from about 30 to about 65 TECU; this sudden increase in VTEC was maintained till about 18:00 UT showing a feature which is different from that of the previous day. There was a high degree of fluctuations with multiple peaks and wave-like features between 10:00 and 18:00 UT. The maximum VTEC value was about 75 TECU at about 14:00 UT on 9 March 2012. The post-sunset fluctuations were not observed; besides, the evening prereversal of plasma level was more enhanced than that of the previous day with about 40 TECU at 23:00 UT. On 10 March, there was an increase of VTEC value in the midnight/post midnight compared to that of the previous day, from a value of about 25 to 35 TECU. The pre-dawn time minimum VTEC value of about 5 TECU got a little more enhanced. The TEC gradually builds up and attained a maximum value of about 75 TECU at 14:00 UT, and later gradually decreases and recovers to initial value it had before the occurrence of the storm, showing the post-evening fluctuations of plasma. The TEC given by PRNs closer to the dip equator seems to be more erratic than the farther ones, especially at evening time. The observed discontinuities in Fig. 2 were due to a lack of data within such time intervals.

Figure 3 shows the storm time VTEC observation from Ile-Ife in comparison to the mean quiet VTEC during the 9 March 2012 storm event. Fig- 


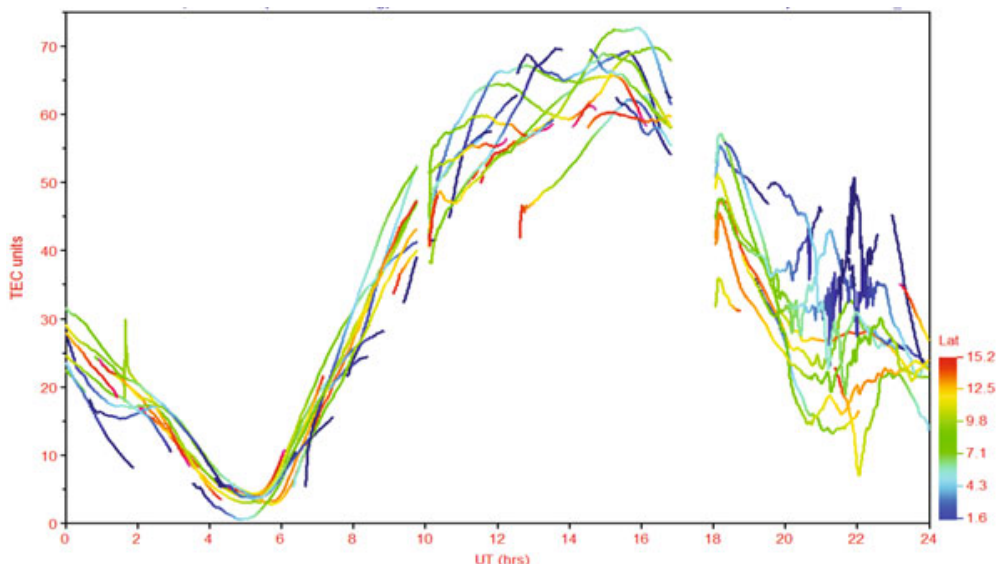

(a)

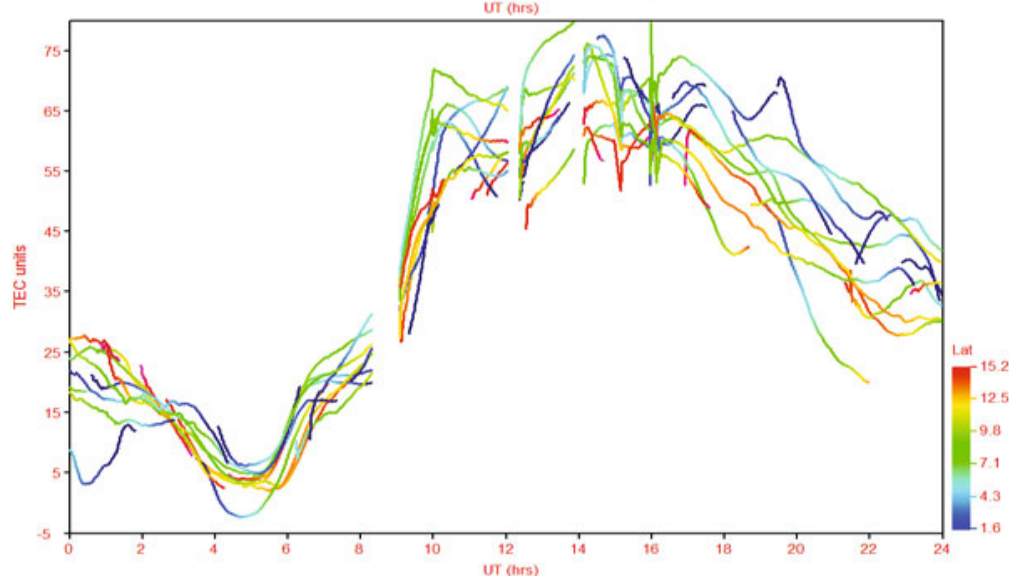

(b)

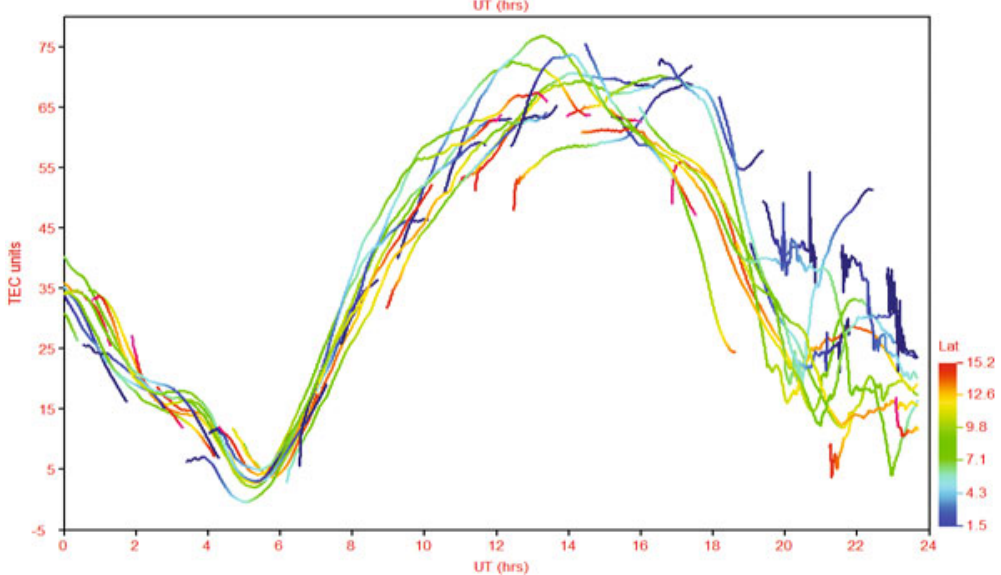

(c)

Fig. 2. The daily VTEC plots for all PRNs for: (a) 8 March 2012, (b) 9 March 2012, and (c) 10 March 2012. The TEC curves are coloured according to the magnetic latitude of the vertical projection of the Ionospheric Pierce Point (IPP) onto the ground. 

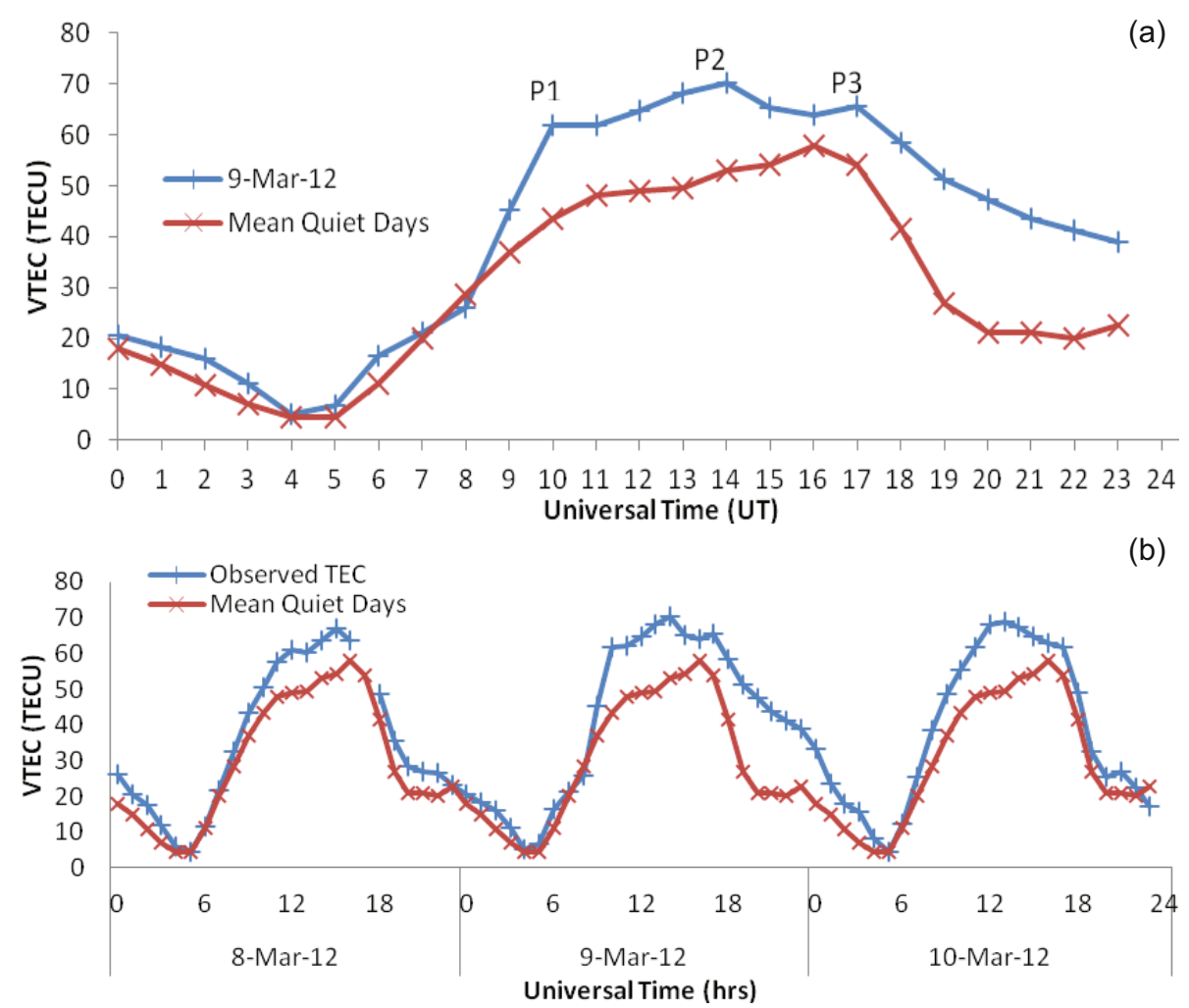

Universal Time (hrs)

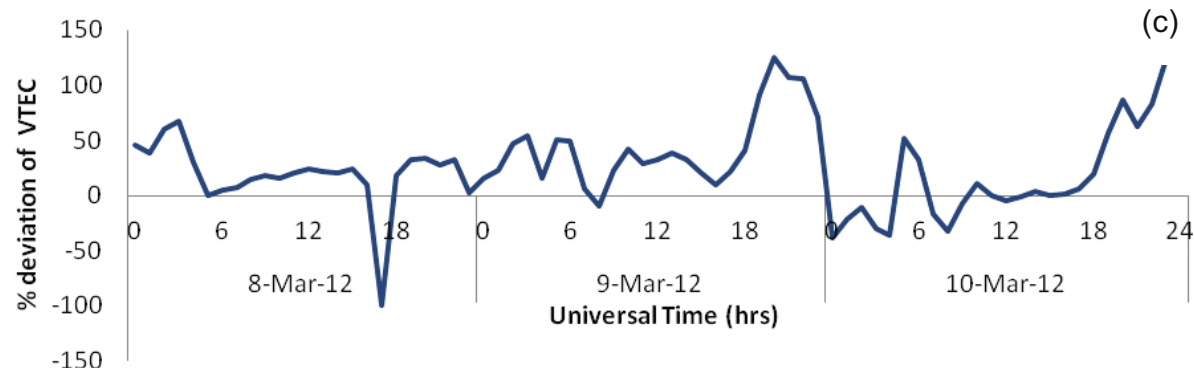

Fig. 3. VTEC observation from Ile-Ife: (a) shows the mean VTEC curve for 9 March 2012 (blue cross) compared with the average of quiet days VTEC (red star); (b) mean VTEC observations on 8-10 March 2012 (blue cross) in comparison with the average of quiet days VTEC (red star); and (c) hourly deviation of VTEC before, during and after the storm day (in percentage).

ure 3a shows the storm VTEC variations for 9 March (blue solid line) compared with mean quiet days VTEC (red dash line) for month of March as observed from Ile-Ife. The curve exhibited VTEC enhancement which had positive ionospheric storm effect all through the day except for the little de- 
pletion that occurred during 08:00 UT. According to Dashora et al. (2009), the most appealing features of storm day VTEC are the multiple peaks and wave like features.

Considering the VTEC curve for the geomagnetic storm day, from 00:00 UT there is a decrease in VTEC value from 20 to 5 TECU at 04:00 UT; thereafter, the VTEC value increased to about $60 \mathrm{TECU}$ at 09:00 UT, which marks the first peak P1. It attained the maximum VTEC value of about 70 TECU at 14:00 UT with a second peak P2, at 5 hours after the minimum $D s t$ index value. There was a little decrease and a later rise in VTEC to 65 TECU at 17:00 UT, thus marking the third peak P3. As could be observed, the maximum VTEC value in average quiet days was about 60 TECU at 16:00 UT while the maximum in mean VTEC on 9 March was about 70 TECU at 14:00 UT. The occurrence of the peak value which occurred earlier on storm day than quiet days has more to do with the electromagnetic dynamics of the equatorial ionosphere. Figure $3 \mathrm{~b}$ shows noticeable difference between the observed VTEC on the storm day and mean quiet days VTEC on the day of the storm compared to the pre-storm and poststorm days. The time of the minimum $D s t$ value corresponds well with the time of the abrupt increase in VTEC at about 08:00-09:00 UT. The enhancement in VTEC was more pronounced during the post-sunset period on 9 March. Figure $3 \mathrm{c}$ shows the hourly VTEC deviations of the storm day VTEC from the mean quiet days VTEC for the period of 8-10 March 2012. The deviation immediately after midnight on 8 March was about $50 \%$ and above till about 03:00 UT when it decreased to 0\% after 05:00 UT. It maintained a value below 20\% till about 17:00 UT when it had a sharp decrease to about $-100 \%$ at $17: 45 \mathrm{UT}$. This sharp decrease is important, being the first notable negative VTEC deviation (depletion) at about 6 hours after the SSC at 11:03 UT on 8 March. The percentage VTEC deviation during the main phase of the storm was generally below $50 \%$, with the maximum percentage deviation of about $120 \%$ at 20:00 UT on 9 March during the recovery phase of the storm.

The results presented in Fig. 3 show that there was an enhancement in VTEC on storm day above the mean quiet days VTEC values for the month of March 2012, with obvious maximum enhancement occurred between the evening and midnight period of 9 March 2012.

Figure 4 shows the $S_{4}$ index plot of the scintillation activity observed by the GPS receiver over Ile-Ife for 8-10 March 2012. It can be clearly seen from the plot that the scintillation activity was weak and ranged between 0.0 and 0.29 , although on the average the activity was below 0.2 . Particularly the periods having $\mathrm{S}_{4}$ index values above 0.2 occurred at about 23:00 UT, 8 March with value $0.29,22: 00 \mathrm{UT}$; 9 March with value $0.22,20: 00 \mathrm{UT}$; and 10 March with value $0.28,20: 00 \mathrm{UT}$. The average $\mathrm{S}_{4}$ index value for 


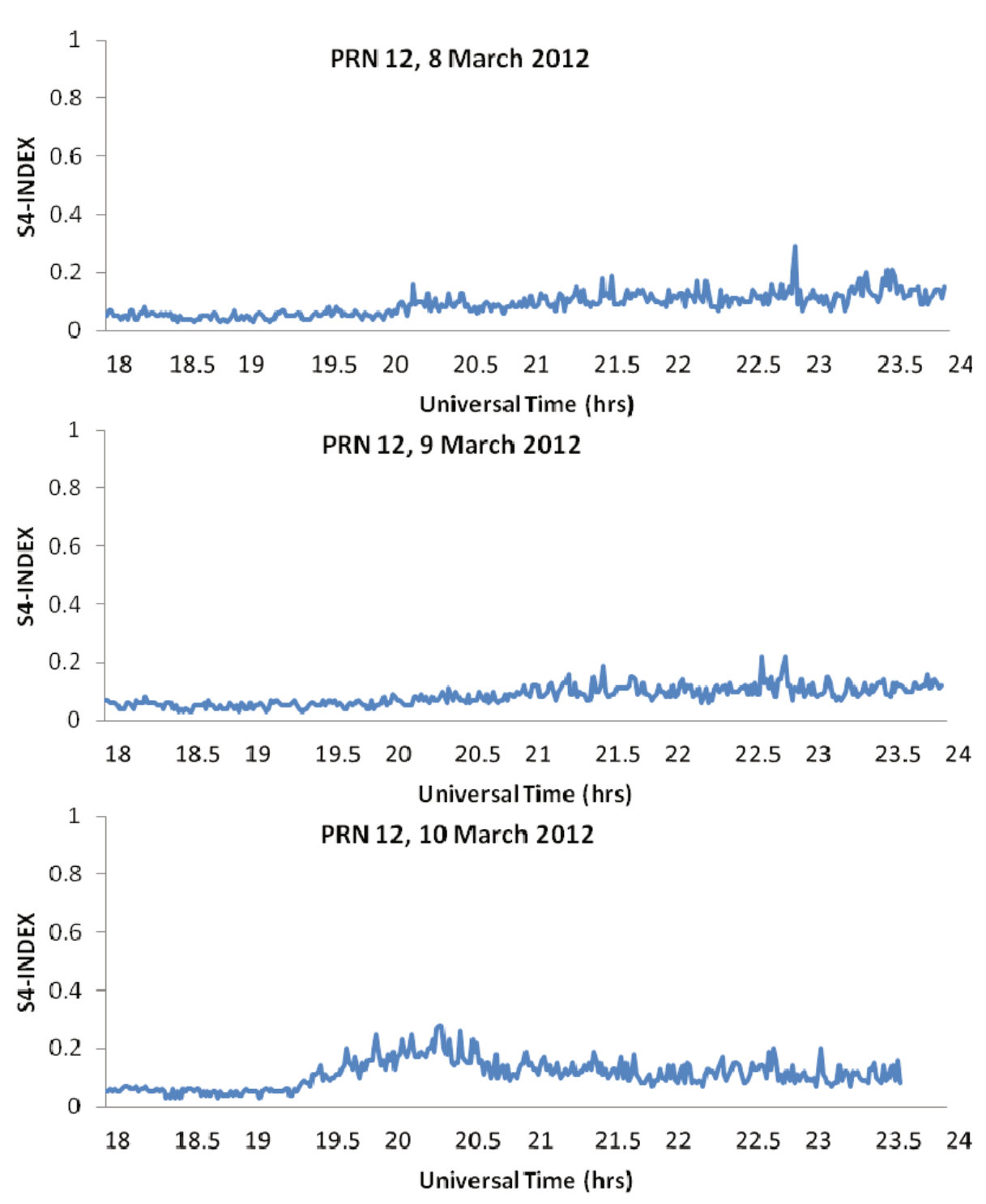

Fig. 4. The variation of $\mathrm{S}_{4}$ index from 8-10 March 2012 for PRN 12.

9 March was lower than the other two days. The $\mathrm{S}_{4}$ index greater than 0.2 is considered to imply a significant level of scintillation (Dashora and Pandey 2005, Ariyibi et al. 2013b). Dashora and Pandey (2005) also reported that the scintillation value of 0.3 is high and significant and its effects on navigational errors should be mitigated. Hence, it is doubtful if this level of activity can have any significant impact on navigational systems. And this shows 
that the geomagnetic storm did not have any significant impact on scintillation activity. This observation follows the results of Ariyibi et al. (2013a) that the occurrence of geomagnetic storm does not necessarily suggest an increase in the level of scintillation at low-latitude region.

\subsection{Solar interplanetary and geomagnetic observations during the storm event of 29 September -3 October 2012}

The interplanetary condition corresponding to the geomagnetic storm that occurred on 1 October 2012 is shown in Fig. 5 for the period 29 September 3 October 2012. There was a gentle decline in solar wind speed on 29 September, from about 320 to $270 \mathrm{~km} / \mathrm{s}$ on 30 September at about 10:00 UT. It rose above $300 \mathrm{~km} / \mathrm{s}$ around noon and later abruptly increased to $400 \mathrm{~km} / \mathrm{s}$ at about midnight of 30 September. The speed later decreased but was still above $300 \mathrm{~km} / \mathrm{s}$ all through the recovery phase. The IMF- $B z$ fluctuated about $0 \mathrm{nT}$ from 29 September till noontime on 30 September. Afterward it turned southward to about $-7 \mathrm{nT}$ at about 16:00-17:00 UT and remained in this direction for about 9 hours. It increased for a short time to $-2 \mathrm{nT}$ at 22:00 UT. It experienced an abrupt southward incursion, which lasted for about 4 hours, with minimum IMF- $B z$ of $-17 \mathrm{nT}$ at 00:00 UT on 1 October and then steeply turned northward to attain $11 \mathrm{nT}$ at about 13:00 UT. The Dst index values were about zero though with occasional rise and fall from $0 \mathrm{nT}$ all through 29 till noon of 30 September. There was a decrease in $D s t$ value from noon till 23:00 UT. It increased shortly to mark the SSC time (23:05 UT) on 30 September, as shown by the arrow in the Dst panel on Fig. 5. From this point the Dst index values began to decrease, reaching the minimum excursion of about $-130 \mathrm{nT}$ observed at 04:00 UT on 1 October, while the recovery phase started immediately on 1 October 2012, and lasted till the following day. The $K p$ index values show low-magnetic activity $(K p<5)$, except in the period of 00:00-02:00 UT where there was intense magnetic activity, with maximum $K p$ value of 7 . The aurora activities for 29 September to 3 October 2012 were quite low, as shown by the AE index. The first abrupt increase in AE occurred 8 hours earlier than the SSC time; this may have been due to an earlier sharp increase in solar wind speed at about 12:00 UT on 30 September. The peak AE value occurred at 04:00 UT during the main phase of the storm.

Deductively from Fig. 5, the solar wind speed was relatively low compared to the solar wind speed of the storm day that occurred on 9 March 2012 , the time of the noticed short abrupt increase in solar wind speed from $316-394 \mathrm{~km} / \mathrm{s}$ and the time of the IMF- $B z$ transition to the southward component correlated with the SSC time. The maximum $K p$ value occurred during the main phase of the storm but 3 hours before the minimum $D s t$ value, 


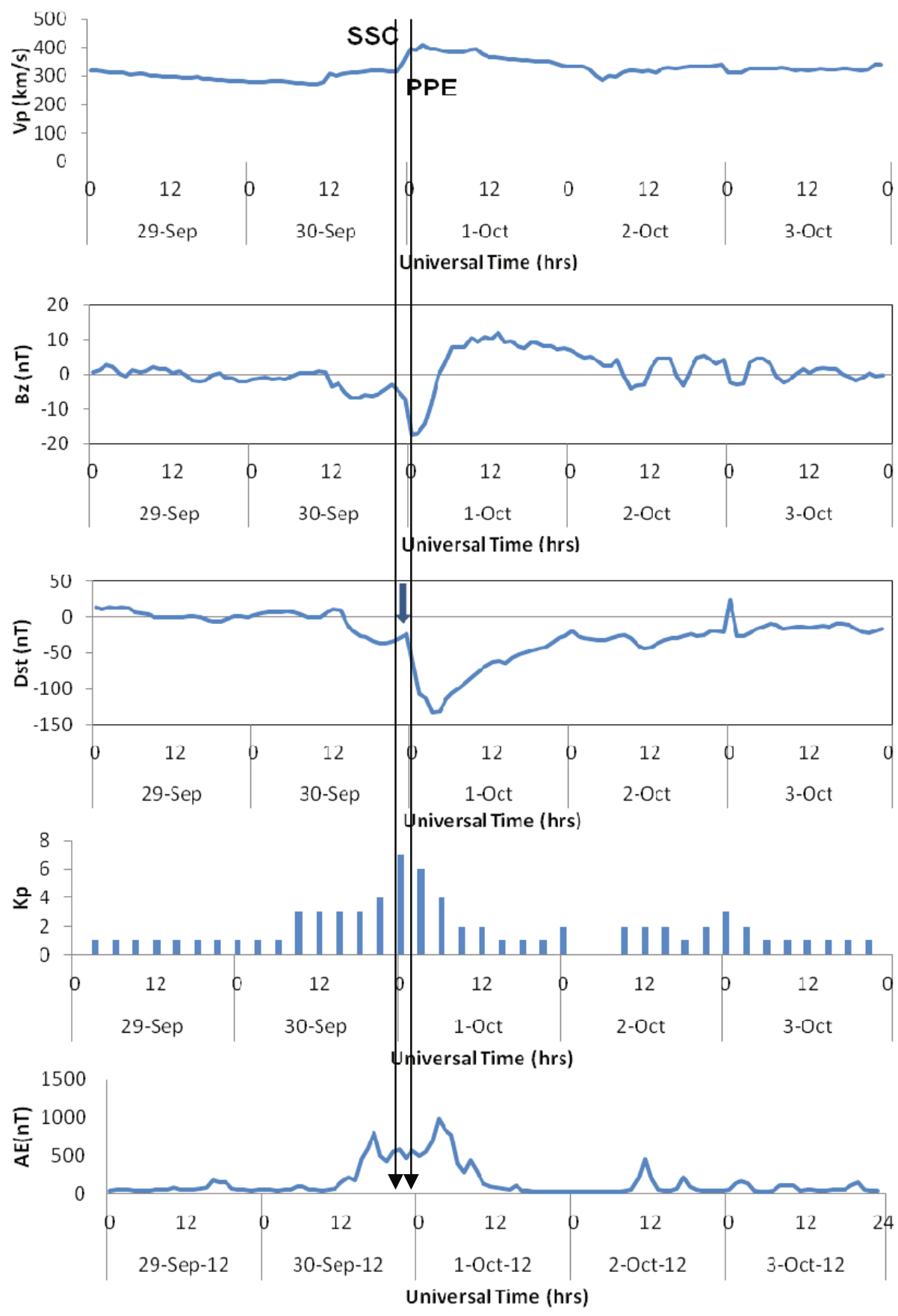

Fig. 5. Interplanetary and geomagnetic observations for 29 September - 3 October 2012. The arrow on Dst is indicating the SSC. 
while a prolonged northward orientation of the IMF- $B z$ was initiated during the main phase of the storm.

\subsection{Ionospheric response to the geomagnetic storm of 1 October 2012: VTEC and $S_{4}$ data}

Figure 6 shows the VTEC plots for all PRNs on 30 September, 1 and 2 October 2012, respectively. The VTEC of 30 September began with about 15 TECU at 00:00 UT and decreased to about 5 TECU between 04:0006:00 UT, from where it gradually rose to a peak value of 65 TECU at about 14:00 UT. It gradually falls to values between 20 and 25 TECU during the night. On 1 October, the previous day's features of VTEC curve were repeated except that there was TEC enhancement during the noon/afternoon period with maximum value of about 65 TECU at about 15:00 UT. On 2 October, there was an increase of VTEC from the initial value of about 15 to 20 TECU at 00:00 UT due to the effect of the storm which was already at the recovery phase. The VTEC values recovered to the pre-storm values from dawn period till the end of the day. There were rapid fluctuations with multiple peaks and wave-like features between 10:00-18:00 UT on 2 October 2012. This observation was also reported by Dashora et al. (2009) for the storm event of 15 May 2005. The maximum VTEC value was about 75 TECU at about 14:00 UT on 1 October 2012. The plasma fluctuations during the evening pre-reversal were observed for the three days with more rapidity on the storm day followed by the day after.

Figure 7 shows the mean quiet days' VTEC observation from Ile-Ile in comparison to the storm time VTEC. Figure 7a shows the VTEC variations of the observed VTEC curve on 1 October (blue colour) and the mean quiet days VTEC curve (pink colour). From 00:00 UT there is a decrease in VTEC value from 10 to 4 TECU at 04:00 UT. Afterward there was a gradual increase in VTEC value to about 64 TECU at 12:00 UT which marks the maximum VTEC at peak, P1. There was a slight decrease to about 61 TECU at 14:00 UT, and later a further decline to about 59 TECU at 16:00 UT. This gradual decrease in VTEC from 64 to 59 TECU at the time interval of 12:0016:00 UT could have been due to the impact of the northward turning of IMF- $B z$, which led to the penetration of a westward electric field in the postmidnight sector. This northward orientation of IMF- $B z$ was maintained from about 03:00 UT till the end of the day. There was a depletion in VTEC values on 1 October between 00:00 and 04:00 UT and at about 19:00 UT, while there was an enhancement in VTEC between the periods of 05:00-18:30 UT and 20:00-23:00 UT. From this plot, it can be observed that the maximum mean quiet days' VTEC value was about 55 TECU at 14:00 UT, while the peak value of VTEC observed for 1 October was about 65 TECU at 


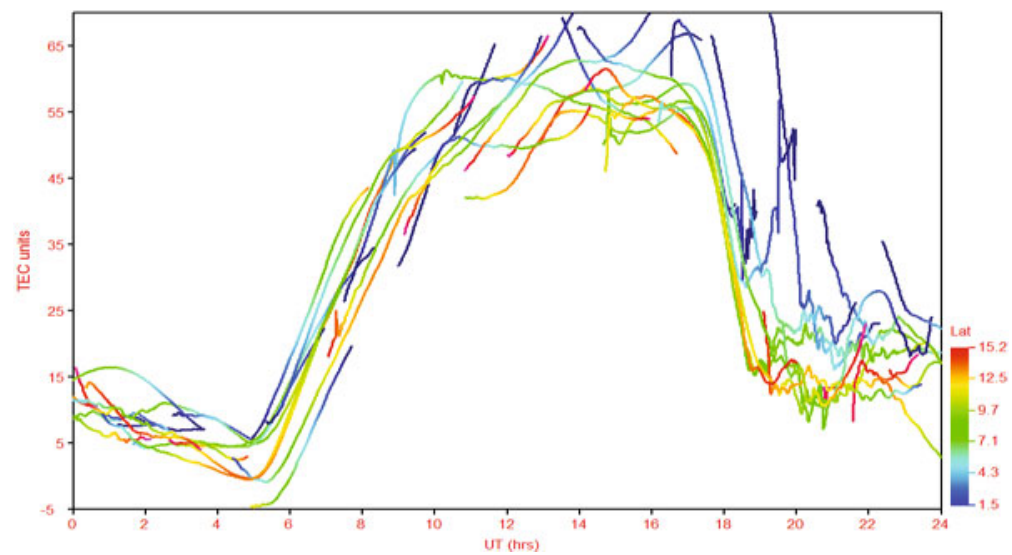

(b)

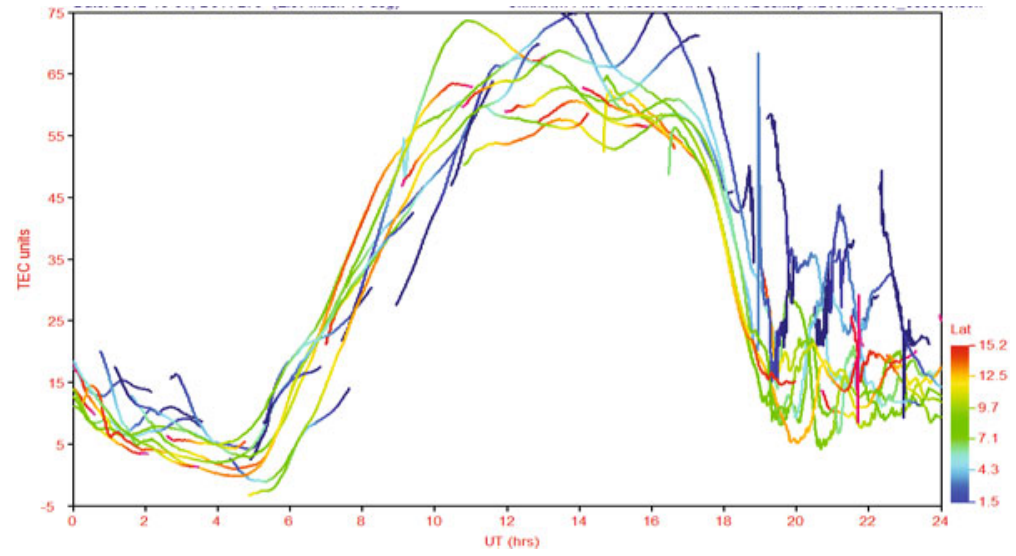

(c)

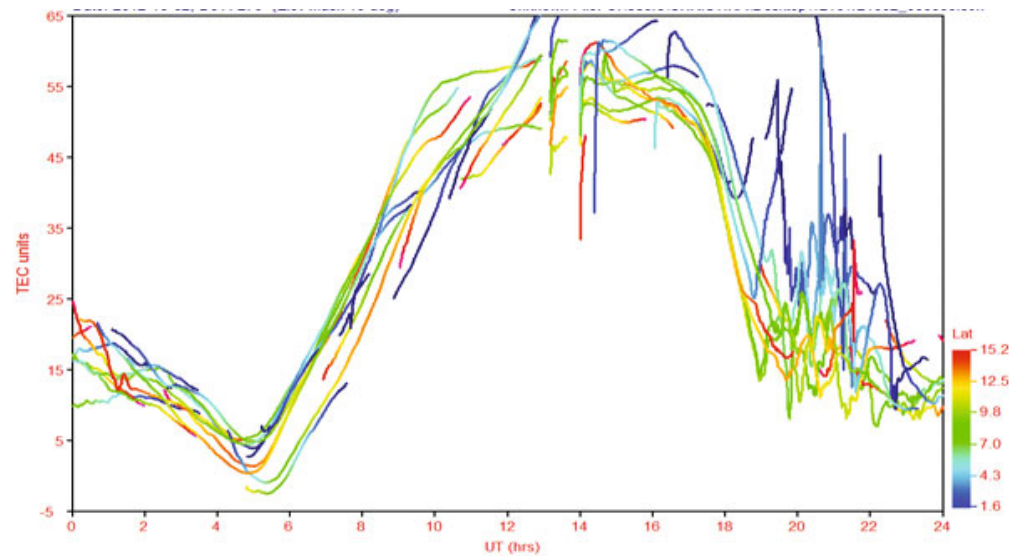

Fig. 6. The daily VTEC plots for all PRNs for the period of: (a) 30 September 2012, (b) 1 October 2012, and (c) 2 October 2012. The TEC curves are coloured according to the magnetic latitude of the vertical projection of the Ionospheric Pierce Point (IPP) onto the ground. 


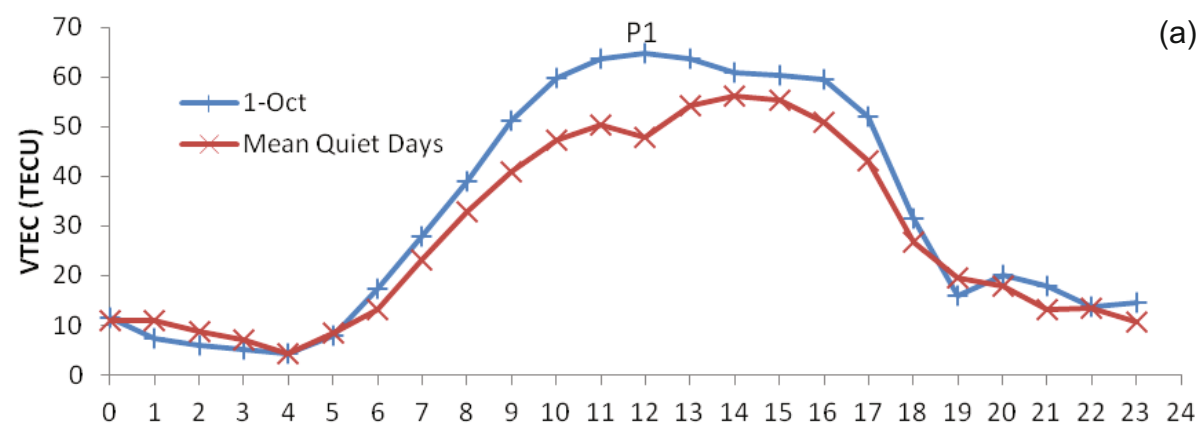

Universal Time (UT)
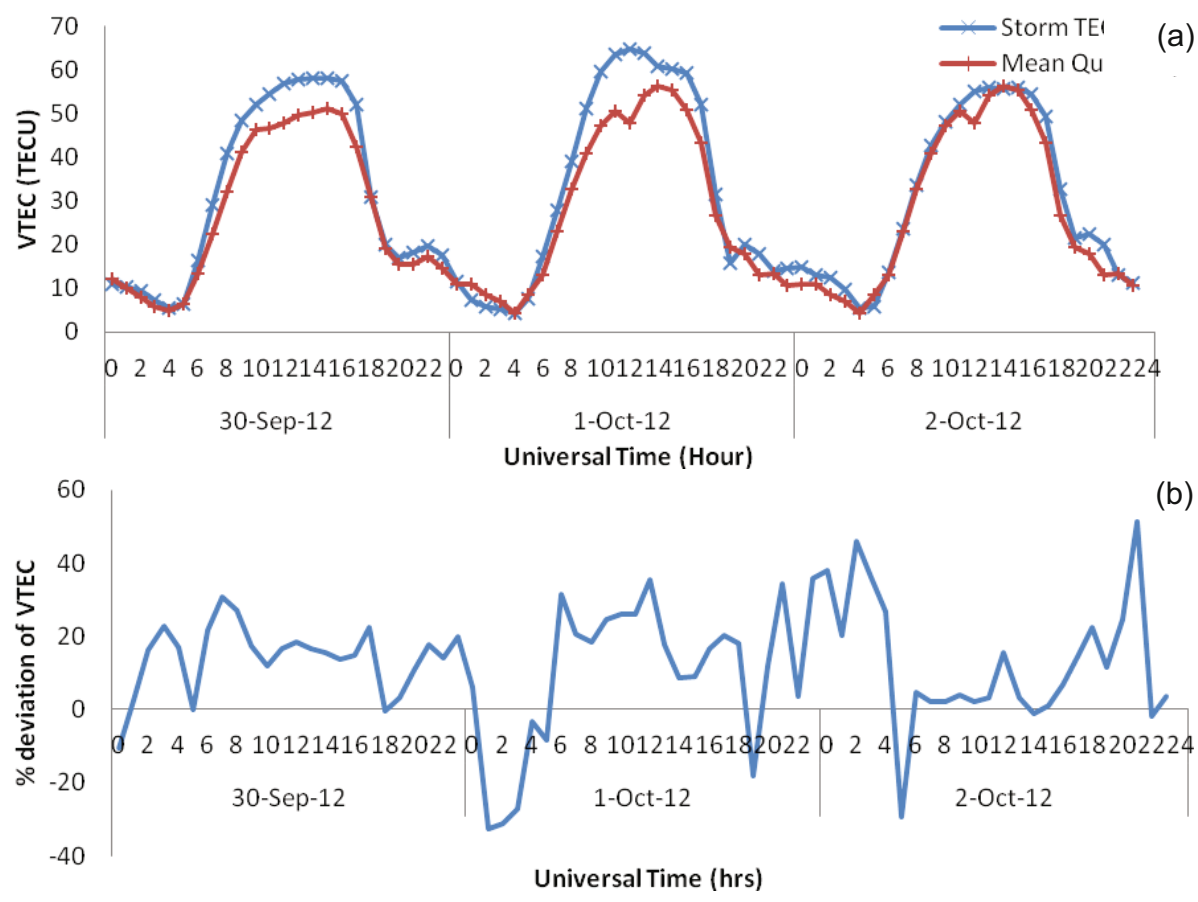

Fig. 7. VTEC observations from Ile-Ife: (a) shows the mean VTEC curve for 1 (c) tober 2012 (blue cross) compared with the average of quiet days VTEC (red s...., (b) mean VTEC observations on 30 September - 2 October 2012 (blue cross) in comparison with the average of quiet days VTEC (red star); and (c) hourly variation of TEC (in percentage).

12:00 UT. Figure $7 \mathrm{~b}$ shows the VTEC variation from 30 September to 2 October 2012 as compared to the mean quiet days VTEC for these months. It is obvious that the level of enhancement for the storm day (1 October) was higher and occurred between 09:00 and 14:00 UT than the other two non- 


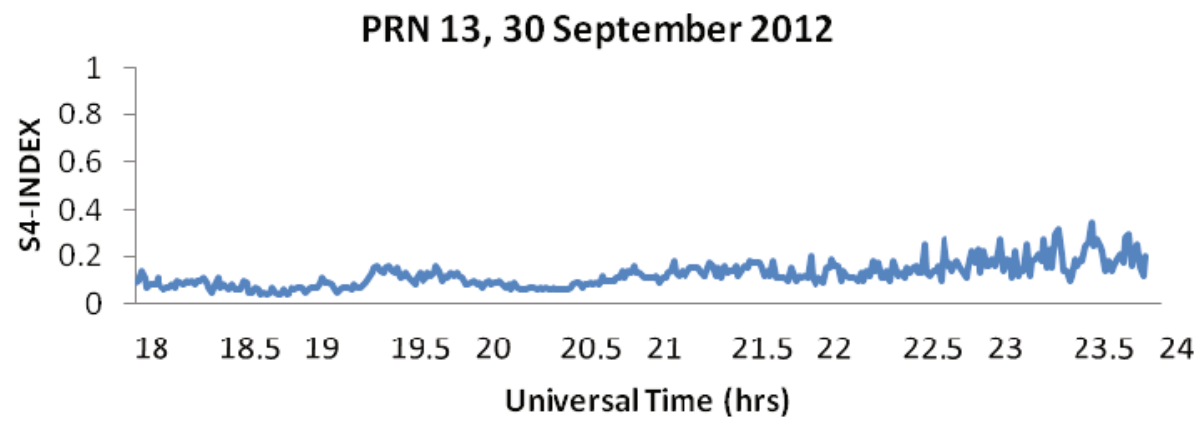

PRN 13, 1 October 2012

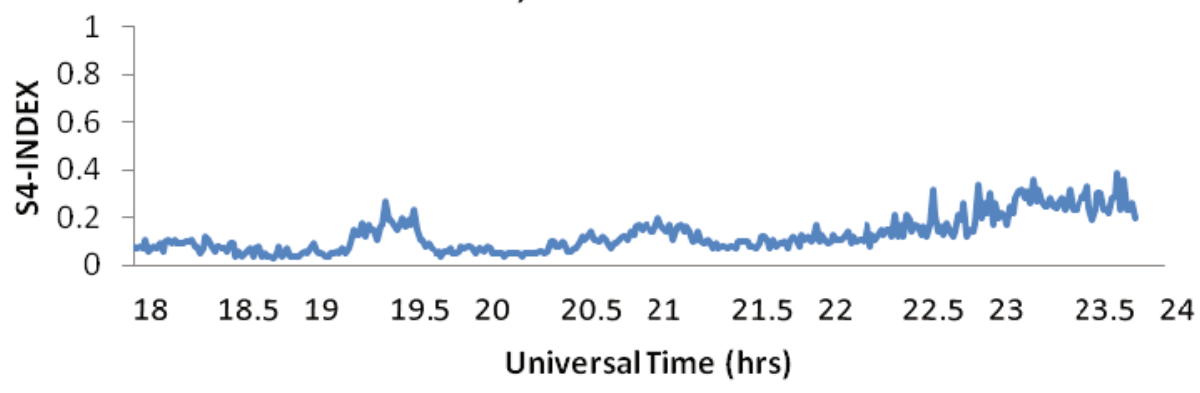

PRN 13, 2 October 2012

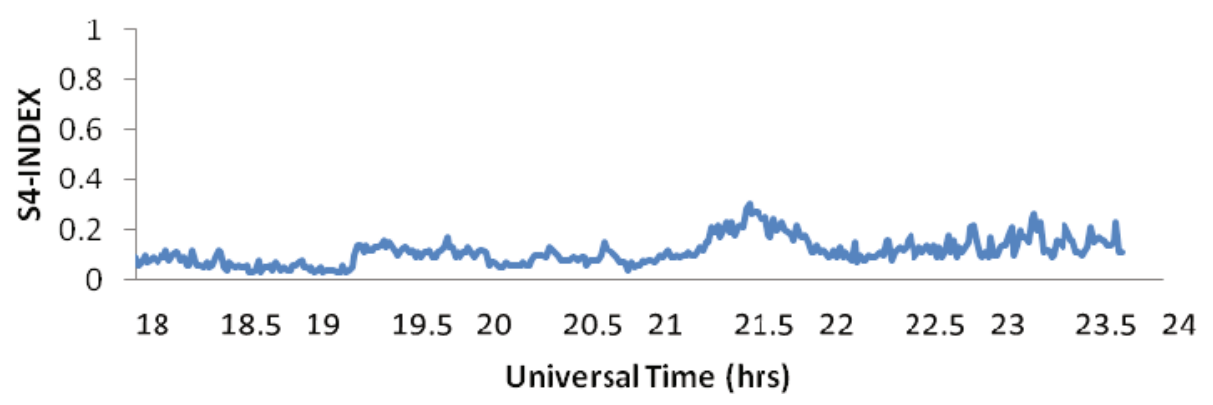

Fig. 8. The variation of $\mathrm{S}_{4}$ index from 30 September to 2 October 2012 for PRN 13.

storm days. Figure 7c shows the percentage deviation of hourly VTEC from 30 September to 2 October. The VTEC deviation began to increase from a value that is lower than $0 \%$ during the post-midnight period of 30 September 2012. There was a negative deviation from about $20 \%$ at $03: 00$ UT to $0 \%$ at 05:00 UT. From here, there was positive deviation of VTEC to about 30\% at 07:00 UT on 30 September. There was also a notable negative deviation to about $-30 \%$ during the post-midnight hours of this same day. This obvious negative percentage deviation in VTEC shortly after the SSC was a feature 
similar to what was observed in the behaviour of percentage deviation in VTEC of the geostorm event of 9 March 2012. The first positive deviation after SSC was observed from 06:00 till 12:00 UT with average value of 40\% and the maximum deviation value of $45 \%$ was observed at 02:00 UT on 2 October during the recovery phase. Generally, from Fig. 7 it can be observed that continued decline in VTEC value from P1 till about 17:00 UT according to Jain et al. (2010) might be due to the disturbance dynamo electric field (DDE) directed westward during the day and eastward during the night, which produces the downward and upward plasma drifts in the lowlatitudes and equatorial ionospheres.

Figure 8 shows the $\mathrm{S}_{4}$ index plot of the scintillation activity for 30 September -2 October 2012. The value ranges from 0.0 to 0.40 with average activity of about 0.30 on 1 October during 23:00 UT. This agrees with the report of Aarons (1991) from daytime scintillations near magnetic dip equator at different longitudes, who concluded that scintillations get enhanced, inhibited or unaffected if the maximum excursion in Dst occurs during postmidnight, afternoon, and sunset hours, respectively. Suggestively one could infer from the results that the increase in $\mathrm{S}_{4}$ index on 1 October could have been due to the impact of storm event.

\section{DISCUSSIONS}

\subsection{The effects of interplanetary and geomagnetic dynamics during the geomagnetic storm events}

The shock that triggers the geomagnetic storm can be identified by the abrupt increase in solar wind speed from 500 to $700 \mathrm{~km} / \mathrm{s}$ at about 11:00 UT on 8 March, as shown in Fig. 1. This marked the time of the sudden storm commencement (SSC) at 11:03 UT, as indicated by the Dst index. Immediately after the SSC, the IMF-Bz oscillated between southward and northward directions and later exhibited a significant southward incursion at 01:00 UT and remained so for about 6 hours. This sudden decrease of IMF- $B z$ to the minimum value of $-16 \mathrm{nT}$ at 07:00 UT caused a sharp decrease in $D s t$ index value at about an hour later and initiated the main phase of the geomagnetic storm. When $B z$ is strongly negative, magnetic reconnection between the IMF and the geomagnetic field produces open field lines which allow mass, energy and momentum to be transferred from the solar wind to the magnetosphere (Davis et al. 1997). This sudden southward turning of the IMF-Bz, from a steady northward configuration, produces a dawn to dusk convection electric field at high latitudes (Kikuchi et al. 1996, 2008). This creates the so-called under-shielding condition and the Region 1 electric field penetrates instantaneously to the equatorial and low latitudes (Kikuchi and Araki 1979). It is identified as sharp electric field perturbations with time scales typically 
shorter than about an hour due to the prompt penetration of solar wind/magnetospheric electric fields to middle, low, and equatorial latitudes (Fejer 2004, Chandra and Rastogi 2011). However, after a steady southward configuration, the IMF- $B z$ turns northward again and the over-shielding condition occurs. In this case the existing Region 2 electric field penetrates the equatorial and low-latitudes (Kikuchi et al. 2008). The enhanced energy deposition during the main phase of the geomagnetic storms and subsequent joule heating in the high latitudes modifies the global thermospheric wind circulation resulting in the disturbance dynamo electric field (Blanc and Richmond 1980). The disturbance dynamo fields manifest on time scales of a few hours to days in the low-latitude ionosphere (Dashora et al. 2009). Such a sudden decrease in IMF- $B z$ and subsequent occurrence of undershielding condition, the prompt penetration electric fields (PPE) are directed eastward during the day and westward during the night, which produces the perturbed upward and downward plasma drifts, respectively, in the low latitudes and equatorial ionosphere (Sastri et al. 1992, 2002; Huang 2008).

Sudden increase (decrease) in AE index and/or a marked decrease (increase) in Sym-H index (the 1 min resolution of Dst index) may be used as proxy to determine the occurrences as well as time of PPE into the equatorial and low latitudes (Huang et al. 2005, Tulasi Ram et al. 2008). Hence, by implication the rate of Dst index showed a rapid decrease with the value of $-3.2 \mathrm{nT}$ per $10 \mathrm{~min}$ at about 02:00 UT on 9 March 2012, suggesting that the sharp decrease in IMF- $B z$ created the under-shielding condition and the PPE occurs at low latitudes around 02:00 UT on 9 March 2012. A similar result to this was reported by Jain et al. (2010) for 15 May 2005 geomagnetic storms. The AE index also confirms this, with sudden increase at about 02:00 UT on 9 March.

The solar wind speed values for 1 October 2012 geomagnetic storm as at the time of SSC and all through the period of the storm were below the expectation. This is in contrast with the reports of Gonzalez et al. (2002) which state that an intense magnetic storm occurs when the solar wind speed is substantially higher than the average speed of $400 \mathrm{~km} / \mathrm{s}$ and Kane (2005) who also showed that moderate and intense storms occurred only when solar wind speed was above $\sim 350 \mathrm{~km} / \mathrm{s}$. The reason is not presently clear. Also the abrupt decrease in IMF- $B z$ and the subsequent occurrence of under-shielding condition makes the convection fields from the high latitudes penetrated into the low latitudes. This can be ascertained by the sharp decrease of Dst index and the rapid decrease of the rate of Dst with time $(-4.58 \mathrm{nT}$ per $10 \mathrm{~min})$ at about 23:00 UT on 30 September, implying that the PPE occurred at the low latitudes around 23:00 UT on 30 September 2012. 


\subsection{The geomagnetic storm effect on VTEC enhancement}

Prompt penetration and disturbance dynamo electric fields, though of smaller magnitude, are the important sources of low-latitude ionospheric electrodynamics disturbances (Chandra and Rastogi 2011). The other main sources come from charged particles responding to the neutral atmosphere in the thermosphere (Adebesin et al. 2012). The high energy input at high latitudes produces waves and changes in thermospheric winds and composition. These changes affect the rate of ions and electrons recombination during a geomagnetic storm. These disturbance waves known as traveling atmospheric disturbances (TADs) travel equatorward with high velocities (Bauske and Prölss 1997) and may result in the uplifting of the F layer (Prölss and Očko 2000). The TADs manifest as traveling ionospheric disturbances (TIDs) in the ionosphere and the effect of TIDs in ionospheric TEC has been observed as increased levels of VTEC. For the intense storm of 9 March 2012, a positive storm effect was observed; the ionosphere over the station first responded with a conspicuous negative TEC deviation at about 5 hours after the SSC. After this the TEC began to respond positively and maximum TEC occurred delayed at 20:00 UT on 9 March; at this time the maximum TEC was about 19 TECU more than the previous day. The gradual increase in TEC after the SSC is followed by a negative deviation of about $9 \%$ at 08:00 UT of 9 March. This depletion coincided with the minimum Dst and 2 hours ahead of minimum IMF- $B z$. Similar results have been observed by Bagiya et al. (2011). The time interval 18:00 UT of 9 March to 00:00 UT of 10 March had low AE index, below $250 \mathrm{nT}$, but correlated well with the period of maximum TEC deviation. The peak P1 in VTEC of 9 March may be attributed to the ionospheric effect of the PPE, which are manifestations of shock waves occurrence and most significantly the southward turning of IMF- $B z$. The peaks $\mathrm{P} 2$ and P3 may be attributed to the presence of TADs at low-latitude regions launched during the main phase of the geomagnetic storm. By this time the short lived PPE effect would have been attenuated. This conclusion is similar to the ones drawn by Dashora et al. (2009).

The point P1 in VTEC value of 1 October 2012 storm marks the point of the maximum TEC. For the intense storm of 1 October 2012, SSC occurred on 23:00 UT, 1-2 hours after the southward turning of IMF- $B z$, which lead to a negative deviation of TEC with minimum value of $32 \%$ at $01: 00 \mathrm{UT}$, about 1 hour after minimum IMF- $B z$. The TEC began to respond positively at 03:00 UT, about 1 hour into the recovery phase and was sustained for about 15 hours (between 03:00 and 18:00 UT) and coincided with a period of high $\mathrm{AE}$ index values. One notable feature is that the time of the high energy input correlated with the time of positive TEC deviation and that there was a time delay before the ionosphere responded. The increase in VTEC started 
from around 05:00 UT to a maximum value at P1 in Fig. 7a appeared rather gradual and not abrupt and the interval of time between the PPE and P1 makes it doubtful as to whether this peak should have been the response due to PPE. Such delayed positive ionospheric storms have been attributed to changes in neutral gas composition (Chandra and Stubbe 1971, Rishbeth 1991). Hence, the P1 in VTEC of 1 October may be attributed to the effect of thermospheric wind, while the continuous decrease in VTEC till about 17:00 UT may be attributed to the disturbance dynamo effect through the penetration of a westward electric field, as observed by the northward turning of IMF-Bz on the second panel in Fig. 5. Sastri et al. (2002) noted that in the post-midnight sector, the penetration of a westward electric field caused the ionospheric F region over India to drift downward and collapse through recombination. The level of VTEC enhancement following the 1 October 2012 storm was not as high as that of 9 March 2012. This may be connected with the magnitude of the Dst value which seems to be lower on 9 March (i.e., more negative) than on 1 October.

\section{CONCLUSIONS}

In this study, the ionospheric responses to two intense geomagnetic storm events on 9 March and 1 October 2012 have been considered. It has been observed that the magnitude, duration and orientation of the IMF- $B z$ played an important role in the dynamics and electrodynamics associated with these geomagnetic storms. In term of response of TEC during these storms, there were obvious positive departures from the mean quiet TEC. While the storm of 9 March 2012 might not have significantly impacted $S_{4}$, that of 1 October 2012 may have had impact on the scintillation activity on this day. The change of ionospheric range delay, which is directly proportional to change of TEC during geomagnetic storms, is a potential limitation in precise positioning using radio waves from GPS; hence, studies like these are important for Satellite Based Navigation Systems. Such studies are also useful for developing the regional TEC model for better understanding and prediction over the equatorial and low latitudes of the African region.

Acknowledgements. The authors wish to express gratitude to the World Data Centre for Geomagnetism, Kyoto University, Japan, and OMNI centre for the provision of data. We acknowledge Prof. P. Doherty of the Institute of Scientific Research, Boston College, USA, and Dr. K. Groves of the Air Force Research Laboratory (AFRL), USA, for making available the GPS device for research in the Department of Physics, Obafemi Awolowo University, Ile-Ife, Nigeria, and G.K. Seemala for making available the GPS TEC software. The support by Abdus Salam International Centre for Theoretical Physics, Trieste, Italy, is also acknowledged. 


\section{References}

Aarons, J. (1991), The role of the ring current in the generation or inhibition of equatorial F layer irregularities during magnetic storms, Radio Sci. 26, 4, 1131-1149, DOI: 10.1029/91RS00473.

Abdu, M.A. (2001), Outstanding problems in the equatorial ionosphere-thermosphere electrodynamics relevant to spread F, J. Atmos. Sol.-Terr. Phys. 63, 9, 869-884, DOI: 10.1016/S1364-6826(00)00201-7.

Adebesin, B.O., S.O. Ikubanni, J.O. Ojediran, and J.S. Kayode (2012), An investigation into the geomagnetic and ionospheric response during a magnetic activity at high and mid-latitude, Adv. Appl. Sci. Res. 3, 1, 146-155.

Adeniyi, J.O. (1986), Magnetic storm effects on the morphology of the equatorial F2-layer, J. Atmos. Terr. Phys. 48, 8, 695-702, DOI: 10.1016/0021-9169 (86)90019-X.

Ariyibi, E.A., E.O. Joshua, and Babatunde A. Rabiu (2013a), Studies of ionospheric variations during geomagnetic activities at the low-latitude station, Ile-Ife, Nigeria, Acta Geophys. 61, 1, 223-239, DOI: 10.2478/s11600-012-0039-3.

Ariyibi, E.A., P. Doherty, A.J. Coster, and E.O. Joshua (2013b), Diurnal variation of TEC and $\mathrm{S}_{4}$ index during the period of low geomagnetic activity at Ile-Ife, Nigeria, Arab. J. Sci. Eng. 38, 7, 1807-1813, DOI: 10.1007/s13369-0120420-1.

Bagiya, M.S., H.P. Joshi, K.N. Iyer, M. Aggarwal, S. Ravindran, and B.M. Pathan (2009), TEC variations during low solar activity period (2005-2007) near the Equatorial Ionospheric Anomaly Crest region in India, Ann. Geophys. 27, 3, 1047-1057, DOI: 10.5194/angeo-27-1047-2009.

Bagiya, M.S., K.N. Iyer, H.P. Joshi, S.T. Thampi, T. Tsugawa, S. Ravindran, R. Sridharan, and B.M. Pathan (2011), Low-latitude ionospheric-thermospheric response to storm time electodynamical coupling between high and low latitudes, J. Geophys. Res. 116, A1, A01303, DOI: 10.1029/2010JA015845.

Bauske, R., and G.W. Prölss (1997), Modeling the ionospheric response to traveling atmospheric disturbances, J. Geophys. Res. 102, A7, 14555-14562, DOI: 10.1029/97JA00941.

Blanc, M., and A.D. Richmond (1980), The ionospheric disturbance dynamo, J. Geophys. Res. 85, A4, 1669-1686, DOI: 10.1029/JA085iA04p01669.

Chandra, H., and R.G. Rastogi (2011), Space weather event of 25 September 1998: Ionospheric response, J. Ind. Geophys. Union 15, 1, 45-59.

Chandra, S., and P. Stubbe (1971), Ion and neutral composition changes in the thermospheric region during magnetic storms, Planet. Space Sci. 19, 5, 491502, DOI: 10.1016/0032-0633(71)90165-6.

D’ujanga, F.M., P. Baki, J.O. Olwendo, and B.F. Twinamasiko (2013), Total electron content of the ionosphere at two stations in East Africa during the 2425 October 2011 geomagnetic storm, Adv. Space Res. 51, 5, 712-721, DOI: 10.1016/j.asr.2012.09.040. 
Dashora, N., and R. Pandey (2005), Observations in equatorial anomaly region of total electron content enhancements and depletions, Ann. Geophys. 23, 7, 2449-2456, DOI: 10.5194/angeo-23-2449-2005.

Dashora, N., S. Sharma, R.S. Dabas, S. Alex, and R. Pandey (2009), Large enhancements in low latitude total electron content during 15 May 2005 geomagnetic storm in Indian zone, Ann. Geophys. 27, 5, 1803-1820, DOI: 10.5194/angeo-27-1803-2009.

Davies, K. (1990), Ionospheric Radio, IEE Electromagnetic Waves Series, Vol. 31, Peter Peregrinus Ltd., London.

Davis, C.J., M.N. Wild, M. Lockwood, and Y.K. Tulunay (1997), Ionospheric and geomagnetic responses to changes in $\mathrm{IMF} \mathrm{B}_{\mathrm{z}}$ : a superposed epoch study, Ann. Geophys. 15, 2, 217-230, DOI: 10.1007/s00585-997-0217-9.

de Siqueira, P.M., E.R. de Paula, M.T.A.H. Muella, L.F.C. Rezende, M.A. Abdu, and W.D. Gonzalez (2011), Storm-time total electron content and its response to penetration electric fields over South America, Ann. Geophys. 29, 10, 1765-1778, DOI: 10.5194/angeo-29-1765-2011.

Fejer, B.G. (2004), Solar wind-magnetosphere effects in the middle and low latitude ionosphere. In: L.M. Zelenyi, M.A. Geller, and J.H. Allen (eds.), Auroral Phenomena and Solar-Terresstrial Relations, CAWSES Handbook - 1, Scientific Committee on Solar-Terrestrial Physics, Boulder 2004, 91-103.

Gonzalez, W.D., J.A. Joselyn, Y. Kamide, H.W. Kroehl, G. Rostoker, B.T. Tsurutani, and V.M. Vasyliunas (1994), What is a geomagnetic storm? J. Geophys. Res. 99, A4, 5771-5792, DOI: 10.1029/93JA02867.

Gonzalez, W.D., B.T. Tsurutani, R.P. Lepping, and R. Schwenn (2002), Interplanetary phenomena associated with very intense geomagnetic storms, J. Atmos. Sol.-Terr. Phys. 64, 2, 173-181, DOI: 10.1016/S1364-6826(01)00082-7.

Hargreaves, J.K. (1995), The solar wind and magnetosphere. In: J.K. Hargreaves, The Solar-Terrestrial Environment, Ch. 5, Cambridge University Press, Cambridge, 132-207.

Huang, C.-S. (2008), Continuous penetration of the interplanetary electric field to the equatorial ionosphere over eight hours during intense geomagnetic storms, J. Geophys. Res. 113, A11, A11305, DOI: 10.1029/2008JA013588.

Huang, C.-S., J.C. Foster, and M.C. Kelley (2005), Long-duration penetration of the interplanetary electric field to the low-latitude ionosphere during the main phase of magnetic storms, J. Geophys. Res. 110, A11, A11309, DOI: 10.1029/2005JA011202.

Jain, A., S. Tiwari, S. Jain, and A.K. Gwal (2010), TEC response during severe geomagnetic storms near the crest of equatorial ionization anomaly, Indian J. Radio Space Phys. 39, 11-24.

Kane, R.P. (2005), How good is the relationship of solar interplanetary plasma parameters with geomagnetic storms? J. Geophys. Res. 110, A2, A02213, DOI: 10.1029/2004JA010799. 
Kikuchi, T., and T. Araki (1979), Horizontal transmission of the polar electric field to the equator, J. Atmos. Sol.-Terr. Phys. 41, 9, 927-936, DOI: 10.1016/ 0021-9169(79)90094-1.

Kikuchi, T., H. Lühr, T. Kitamura, O. Saka, and K. Schlegel (1996), Direct penetration of the polar electric field to the equator during a DP 2 event as detected by the auroral and equatorial magnetometer chains and the EISCAT radar, J. Geophys. Res. 101, A8, 17161-17173, DOI: 10.1029/96JA01299.

Kikuchi, T., K.K. Hashimoto, and K. Nozaki (2008), Penetration of magnetospheric electric fields to the equator during a geomagnetic storm, J. Geophys. Res. 113, A6, A06214, DOI: 10.1029/2007JA012628.

Lima, W.L.C., F. Becker-Guedes, Y. Sahai, P.R. Fagundes, J.R. Abalde, G. Crowley, and J.A. Bittencourt (2004), Response of the equatorial and lowlatitude ionosphere during the space weather events of April 2002, Ann. Geophys. 22, 9, 3211-3219, DOI: 10.5194/angeo-22-3211-2004.

Lobzin, V.V., and A.V. Pavlov (2002a), Solar zenith angle dependencies of F1layer, NmF2 negative disturbance, and G-condition occurrence probabilities, Ann. Geophys. 20, 11, 1821-1836, DOI: 10.5194/angeo-20-1821-2002.

Lobzin, V.V., and A.V. Pavlov (2002b), G condition in the F2 region peak electron density: a statistical study, Ann. Geophys. 20, 4, 523-537, DOI: 10.5194/ angeo-20-523-2002.

Lynn, K.J.W., M. Sjarifudin, T.J. Harris, and M. Le Huy (2004), Combined TOPEX/Poseidon TEC and ionosonde observations of negative low-latitude ionospheric storms, Ann. Geophys. 22, 8, 2837-2847, DOI: 10.5194/angeo22-2837-2004.

Malik, R., S. Sarkar, S. Mukherjee, and A.K. Gwal (2010), Study of ionospheric variability during geomagnetic storms, J. Indian Geophys. Union 14, 1, 4756.

Olawepo, A.O. (2013), Response of ionospheric N(h) profiles over Ilorin to moderate geomagnetic storms, Ife J. Sci. 15, 3, 509-521.

Olawepo, A.O., and J.O. Adeniyi (2012), Ionosphere's F2-layer response to 2006 geomagnetic storm at Ilorin, Nigeria, Afr. Rev. Phys. 7, 0031, 277-281.

Pavlov, A.V., S. Fukao, and S. Kawamura (2004), F-region ionospheric perturbations in the low-latitude ionosphere during the geomagnetic storm of 25-27 August 1987, Ann. Geophys. 22, 10, 3479-3501, DOI: 10.5194/angeo-223479-2004.

Pincheira, X.T., M.A. Abdu, I.S. Batista, and P.G. Richards (2002), An investigation of ionospheric responses, and disturbance thermospheric winds, during magnetic storms over South American sector, J. Geophys. Res. 107, A11, SIA 12-1 - SIA 12-17, DOI: 10.1029/2001JA000263.

Prölss, G.W., and M. Očko (2000), Propagation of upper atmospheric storm effects towards lower latitudes, Adv. Space Res. 26, 1, 131-135, DOI: 10.1016/ S0273-1177(99)01039-X. 
Rishbeth, H. (1991), F-region storms and thermospheric dynamics, J. Geomagn. Geoelectr. 43, Suppl. 1, 513-524, DOI: 10.5636/jgg.43.Supplement1_513.

Sastri, J.H., K.B. Ramesh, and H.N.R. Rao (1992), Transient composite electric field disturbances near dip equator associated with auroral substorms, Geophys. Res. Lett. 19, 14, 1451-1454, DOI: 10.1029/92GL01447.

Sastri, J.H., N. Jyoti, V.V. Somayajulu, H. Chandra, and C.V. Devasia (2000), Ionospheric storm of early November 1993 in the Indian equatorial region, J. Geophys. Res. 105, A8, 18443-18455, DOI: 10.1029/1999JA000372.

Sastri, J.H., J. Niranjan, and K.S.V. Subbarao (2002), Response of the equatorial ionosphere in the Indian (midnight) sector to the severe magnetic storm of July 15, 2000, Geophys. Res. Lett. 29, 13, 29-1-29-4, DOI: 10.1029/ 2002 GL015133.

Sobral, J.H.A., M.A. Abdu, W.D. Gonzalez, B.T. Tsurutani, I.S. Batista, and A.L. Clua de Gonzalez (1997), Effects of intense storms and substorms on the equatorial ionosphere/thermosphere system in the American sector from ground-based and satellite data, J. Geophys. Res. 102, A7, 14305-14313, DOI: $10.1029 / 97 J A 00576$.

Tulasi Ram, S., P.V.S. Rama Rao, D.S.V.V.D. Prasad, K. Niranjan, S. Gopi Krishna, R. Sridharan, and S. Ravindran (2008), Local time dependent response of postsunset ESF during geomagnetic storms, J. Geophys. Res. 113, A7, A07310, DOI: 10.1029/2007JA012922.

Received 15 July 2014

Received in revised form 18 January 2015

Accepted 22 April 2015 